\title{
Women in thoracic surgery: Asian perspective
}

\author{
Aki K. Kobayashi \\ Department of Thoracic Surgery, Hyogo College of Medicine, Hyogo, Japan \\ Correspondence to: Aki K. Kobayashi, BSc, MSc, MD. Department of Thoracic Surgery, Hyogo College of Medicine, 1-1, Mukogawa-cho, \\ Nishinomiya, Hyogo, 663-8501 Japan. Email: ak-kobayashi@hyo-med.ac.jp.
}

\begin{abstract}
There is a significant shortage of surgeons in Japan similar to many other countries. There are 40,267 registered surgeons for Japan Surgical Society, among them 23,723 are board certificated, and 7,246 are certified instructors. A total of 3,207 surgeons are members of The Japanese Associations for Chest Surgery, and 245 (7.6\%) are female surgeons. Approximately 8,000 medical students graduate annually with medical license. The number of newly registered residents and surgeons has recently been declining overall in the last two decades, however, the percentage of female physicians entering into surgery has been increasing gradually along with increasing number of female medical students entering the medical schools and colleges. With regard to the issue of gender gap, our country is ranked as low as 121 out of 153 countries according to global gender gap report 2020 by World Economic Forum, dropping down from 110 out of 149 countries from previous report in 2018. As the numbers of female colleagues in our workplace increases, we must consider what we can do to build a better working environment for them that is more inclusive and supports their career. In this review, the brief history of surgery and female surgeons is described as well as current situations of female surgeons today in Japan.
\end{abstract}

Keywords: Women surgeons; gender gap

Submitted Feb 03, 2020. Accepted for publication Jul 10, 2020.

doi: 10.21037/jtd-2020-wts-04

View this article at: http://dx.doi.org/10.21037/jtd-2020-wts-04

\section{Introduction}

The continent of Asia, covers more than 40 countries. In this article, I focus on the Japanese perspective of thoracic surgery. The history of women in surgery in Japan dates back to the 1880's. The path that our pioneers traveled was neither easy nor pleasant, yet through relentless effort, we have made progress. Gender-based barriers have long been a problem recognized by the Japanese Government who acted by establishing several legislative systems to decrease the gender gap in our society beginning in 1999. Since then, however, there has been only incremental change (1), yet we remain hopeful that more change will come in the near future.

\section{History of surgery in Japan}

In 1552, Luis de Aimeida, a Portuguese physician, brought Western medicine and surgery to Japan. He was also a missioner and merchant, and with his wealth, he built orphanages and hospitals practicing surgery in Nagasaki, Japan. Following this, medicine was taught at small schools in Japan using textbooks brought from the Western world. According to the existing record, Seishu Hanaoka resected breast cancer under general anesthesia on 14 November 1804 with extract of Datura metel. By 1875, a medical licensing system was established in Japan. Women, however were not allowed to apply for the licensing examination until 1884. The very first female surgeon in Japanese history was Ine Kusumoto, the daughter of Kusumoto Taki and Philipp Franz Balthasar von Siebold. Von Siebold was a German physician, who lived in Japan from 1823 to 1828, during the era of national isolation. Dr. Kusumoto studied medicine and became the very first female gynecologist in Japan. However, she was never permitted to take the licensing examination. The first Japanese woman officially certified in surgery was Ginko Ogino, who started her life in medicine after she contracted gonorrhea from her husband. 
She was inspired to become a physician after the shame she felt when examined and treated by a male physician. She finished medical school and successfully passed the licensing examination in 1884.

\section{Medical schools and training in surgery}

There are 51 national, prefectural and other public medical colleges, and 31 private medical colleges in Japan. Students apply for each school after compulsory education and 3 years of high school education. The percent of female medical students enrolled is approximately $50 \%$ (18\% to $100 \%$ as of Tokyo Women's Medical university) today. Over 9,000 medical students graduate every year and more than $80 \%$ qualify for national licensing examinations. In 2004, clinical internship was first introduced and new graduates, who plan to be involved in clinical practice are required to go through a 2-year internship before choosing their field of specialty. Before 2004, graduates entered departments directly and began surgical training immediately. Internship curricula have changed over the years, however, experience in thoracic surgery has not been a requirement in surgical training. Few residents undertake an elective training program in thoracic surgery. Most junior doctors have no opportunity to see what thoracic surgeons do in the operation theater at all. This means there is a lack of early exposure in internship which translates into lack of interest in the later years. Recently, the number of residents choosing to train in surgery has been declining which contributes to the current surgeon shortage in Japan.

To obtain board certification in surgery, junior surgeons spend at least 3 years of training in surgery after the first 2 years of their first internship. He or she has to perform at least 120 surgeries and train in 10 divisions of surgery, including thoracic surgery, gastrointestinal surgery, and damage control surgery. After a minimum of 3 years in training in thoracic surgery and at least one academic paper published, he or she is eligible for the examination for a board certificate in thoracic surgery.

According to the Ministry of Health, Labor, and Welfare biannual survey data, at the end of 2019, there were 327,210 registered physicians in Japan of which 255,452 $(78.1 \%)$ were male and $71,758(21.9 \%)$ female. In the last decade, there has been an increase in the number of female physicians registered in Japan. As for thoracic surgeons, 1,999 were registered, which was $0.6 \%$ of total number of physicians in Japan. A total of 1,507 of these had been board certified in thoracic surgery. Of thoracic surgeons, 1,982 were working in hospitals and 17 were working in clinics. Ninety-one percent of surgeons at hospitals were male and $8.8 \%$ are female. The average age of thoracic surgeons was 44.9 years old.

From the questionnaire conducted by the Japanese Association of Chest Surgery (JACS), the total number of registered surgeons was 3,207 and 254 (7.6\%) were women in 2017. Among registered members of the association, $25 \%$ are councilor, $24 \%$ board certified and $51 \%$ have no qualification among male members, whereas $6 \%$ are councilor, $20 \%$ board certified and $74 \%$ of the registered member have no qualifications among women surgeon. In spite of a decrease in the number of trainees in surgery overall, the ratio of new female residents registered to the association of chest surgery is gradually increasing in recent years (Figure 1). The number of surgeon members within JACS differs from the numbers reported in the national survey. This is partly because non-practicing surgeons may have been included in JACS membership and general surgeons may have multiple registered specialties in the national survey.

According to the global gender gap report 2020 by World Economic Forum (ISBN-13: 978-2-940631-03-2), Japan ranked 121 out of 153 countries in gender pay gap. Previous data showed Japan ranked 110. Thus it seems that Japan has not improved its gender disparity despite the fact that the Japanese government has been encouraging the promotion of gender equality since 1999. Nomura et al. (2) conducted a survey with the Japanese Ministry and showed that female medical residents had less confidence in their clinical training without any inferiority in their performance. Like other countries, women surgeons experience gender inequality in Japan (3). There are fewer numbers of councilors or higher ranks occupied by female physicians (4) and a significant salary gap has also been documented (5). Nomura et al. discussed that being married and having children were significantly associated with part-time practice among female physicians, and being in a part-time position was significantly associated with strong perceptions of gender-based obstacles. Recognizing gender bias and limitations of the glass-ceiling, attempts have been made to create a work environment within Japan that is more supportive of women. For instance, most large societies holding conferences within Japan now provide lactation rooms for new mothers. Additionally, groups working on gender equality within institutions are becoming more common and help to promote awareness in our society. To date, progress towards gender equality 


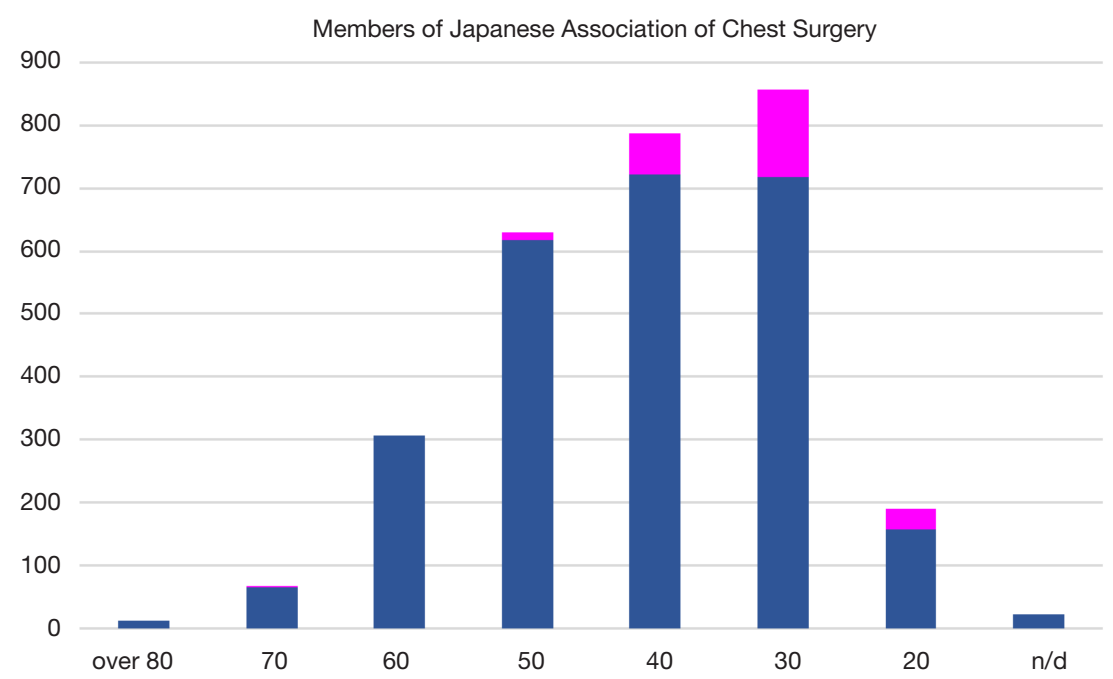

Figure 1 Age distribution of registered members for Japanese Association of Chest Surgery in 2019. Blue box shows male and pink box female.

in surgery in Japan has been slow, however, the number of women physicians entering the field of surgery is providing a catalyst for change. We have great pioneers in our history as well as our society currently who are helping to champion the cause.

\section{Participation equality}

In December 2018 events from Japan made world news with shocking headlines. Scores from medical school entrance examinations for female students were manipulated to deliberately exclude them from admission. At least nine medical schools were involved. This was overt gender discrimination. To make things worse, there were those who argued in favor of the practice based on the fallacy that women tend to leave their positions early due to maternity leave or marriage, or the notion that long hours of hard work are not suitable for women. The statements were difficult to hear in press conferences but even more difficult to live through for the eager female medical students whose medical careers had been denied. Gender discrimination begins early in medical training. Women training in thoracic surgery, have less chance to take part in academic work and get promoted in the workplace. When they have families, things tend to get even harder. It is almost impossible to return to work after maternity leave and resume training in surgery due to lack of resources and support. This eventually leads to fewer numbers of female surgeons with board certification, and very small number of female councilors.

As for the medical school admissions scandal, there are no excuses to justify the practice and every effort should be made for equal opportunities for students and righting the wrong that has been done. To date, only private schools were identified by investigations, but one can wonder what other practices are in place to perpetuate the inequity. Throughout Japan, there are traditional cultural beliefs that women should remain in the home doing housekeeping and taking care of children as is the case in many other countries in the world. These beliefs fuel discrimination such that female physicians experience harassment in job interviews or once in the workplace including discriminatory questions such as whether the surgeon is married, their plans to have children or even how long they wish to work at the position they have applied to.

Some even believe that women do not have the physical stamina to perform long operations leading to more discriminatory practices. Still others believe that women surgeons are more likely to leave practice so there is no use teaching and training them. It is true that some female physicians have to leave medicine, but this is mainly because it is not common for Japanese men to use maternity leave today thus leaving the majority of childcare activity to that of women surgeons as mothers. All of these biases, work against efforts to increase the number of female surgeons and further undermine Japan's ability to supply its medical workforce in the future.

In my experience there had always been equal distribution of night duties among residents unless you 
were pregnant. So, women were given equal time for night duty but relatively less opportunity in performing surgery than our male counterparts. Equitable distribution of clinical opportunities and experience during surgical training relies upon senior doctors and mentors who oversee trainees of all levels to ensure they are able to fulfill the requirements for certification. They should be familiar with the training system and all requirements in order to perform this duty well. And at the same time, we, female surgeons must be our own champions, raising our hands and seizing opportunities. Being too polite to speak out is not a virtue in clinical medicine. Japan is very similar to many other countries around the world in terms of female surgeon representation. Sobering as it is, this has also been a great opportunity to realize the common experiences of female surgeons throughout the world as we work to build better working environments in our societies and the field of thoracic surgery. I would like to show my immense gratitude to the editors and all involved in the symposium held in Dublin for giving me this eye-opening opportunity.

\section{Acknowledgments}

The data shown in figure in this article and at the symposium was provided Dr Rie Nakahara from Japanese Association of Chest Surgery.

Funding: None.

\section{Footnote}

Provenance and Peer Review: This article was commissioned by the Guest Editors (Cecilia Pompili and Leah Backhus) for the series "Women in Thoracic Surgery" published in fournal of Thoracic Disease. The article was sent for external peer review organized by the Guest Editors and the editorial office.

Conflicts of Interest: The author has completed the ICMJE uniform disclosure form (available at http://dx.doi. org/10.21037/jtd-2020-wts-04). The series "Women in Thoracic Surgery" was commissioned by the editorial office without any funding or sponsorship. The author has no other conflicts of interest to declare.

Ethical Statement: The author is accountable for all aspects of the work in ensuring that questions related to the accuracy or integrity of any part of the work are appropriately investigated and resolved.

Open Access Statement: This is an Open Access article distributed in accordance with the Creative Commons Attribution-NonCommercial-NoDerivs 4.0 International License (CC BY-NC-ND 4.0), which permits the noncommercial replication and distribution of the article with the strict proviso that no changes or edits are made and the original work is properly cited (including links to both the formal publication through the relevant DOI and the license). See: https://creativecommons.org/licenses/by-nc-nd/4.0/.

\section{References}

1. Ministry of Health and Labour Welfare. Survey of physicians, dentists, and pharmacists (in Japanese). Available online: www.e-stat.go.jp

2. Nomura K, Yano E, Fukui T. Gender differences in clinical confidence: a nationwide survey of resident physicians in Japan. Acad Med 2010;85:647-53.

3. Nomura K, Gohchi K. Impact of gender-based career obstacles on working status of women physicians in Japan. Soc Sci Med 2012;75:1612-6.

4. Tomizawa Y. Women in surgery: little change in gender equality in Japanese medical societies over last 3 years. Surg Today 2013;43:1202-5.

5. Okoshi K, Nomura K, Taka F, et al. Suturing the gender gap: Income, marriage, and parenthood among Japanese Surgeons. Surgery 2016;159:1249-59.
Cite this article as: Kobayashi AK. Women in thoracic surgery: Asian perspective. J Thorac Dis 2021;13(1):456-459. doi: 10.21037/jtd-2020-wts-04 